\title{
AUTOMOBILE COMPONENTS: LITHIUM AND COBALT. EVIDENCE OF PERSISTENCE
}

\author{
Manuel Monge, Francisco de Vitoria University (UFV), Madrid, Spain \\ and
}

Luis A. Gil-Alana*, University of Navarra, Pamplona, Spain

\begin{abstract}
This paper deals with the analysis of persistence in the prices of two technologically important metals, namely, lithium and cobalt. Along with them, we also examine four additional series corresponding to World, European, US and Japanese automobiles and component indices. For this purpose, we use long memory techniques based on fractional integration and cointegration. The results indicate that all the series are highly persistent, though we do not find any evidence supporting long run equilibrium relationships between the variables examined.
\end{abstract}

Keywords: Lithium; cobalt; automobiles and components; fractional integration; fractional cointegration; persistence

JEL Classification: C22; O13; Q21; F01; E30.

$\begin{array}{ll}\text { Correspondence author: } & \text { Dr. Manuel Monge } \\ & \text { Francisco de Vitoria University } \\ & \text { Faculty of Economics and Business Administration } \\ & \text { E-28223 Madrid } \\ & \text { SPAIN }\end{array}$

Email: manuel.monge@ufv.es

\footnotetext{
* The second-named author gratefully acknowledges financial support from the Ministerio de Economía y Competitividad (ECO2017-85503-R). Comments from the Editor and an anonymous reviewer are gratefully acknowledged.
} 


\section{Introduction}

Electric vehicles (EV), including Battery Electric Vehicle (BEV), Hybrid Electric Vehicle (HEV), Plug-in Hybrid Electric Vehicle (PHEV), Fuel Cell Electric Vehicle (FCEV) are becoming more commonplace in the transportation sector in recent times. According to Hockerts and Wüstenhagen (2010) and Johnson and Suskewicz (2009), sustainable technologies hold the promise to reduce harmful and use resources more efficiently.

In line with the above argument, electric vehicles are gaining popularity due to their contribution in reducing greenhouse gas (GHG) emissions. According to the IPCC (2007), energy-related greenhouse gas emissions, mainly from fossil fuel combustion for heat supply, electricity generation and transport, account for around $70 \%$ of total emissions including carbon dioxide, methane and some traces of nitrous oxide. Yong et al. (2015) argued that in 2009, the transportation sector emitted $25 \%$ of the GHGs produced by energy related sectors. Also, the EVs are quiet to operate, and do not have the fuel costs associated with conventional vehicles.

In accordance with the World Oil Outlook (2017), governments around the globe have started creating incentives to promote electric mobility, especially in urban areas. Nevertheless, since EVs are still far more expensive than comparable ICE-based cars and in view of the poorly developed charging infrastructure, the sales share of EVs remained low for 2016. According to the same report, this may change substantially in the future, until 2040. OPEC's report estimates fast adopting EVs in OECD Europe (33\%), OECD America (35\%), OECD Asia Oceania (31\%) and China (29\%). This group of regions represents more than two-thirds of all global passenger car sales. 
It is in this scenario that the essential metals lithium (Li) and cobalt (Co) that are being used for the energy storage and the electric mobility are taking on an increasingly strategic role in the use in the EVs batteries.

The most important technological advancement that has had the greatest impact on the adoption of renewables is that of energy storage. The intrinsic intermittency of alternatives, as compared to the reliable, tangible nature of fossil fuels, has been one of the major impediments to their suitability for meeting the world's energy needs. Lithium and cobalt are technologically important metals that have many diverse uses. The use of lithium is currently dominated by the use for batteries $(39 \%)$. The same case occurs with cobalt, which is used globally in the manufacture of cathode materials for rechargeable batteries $(30 \%)$.

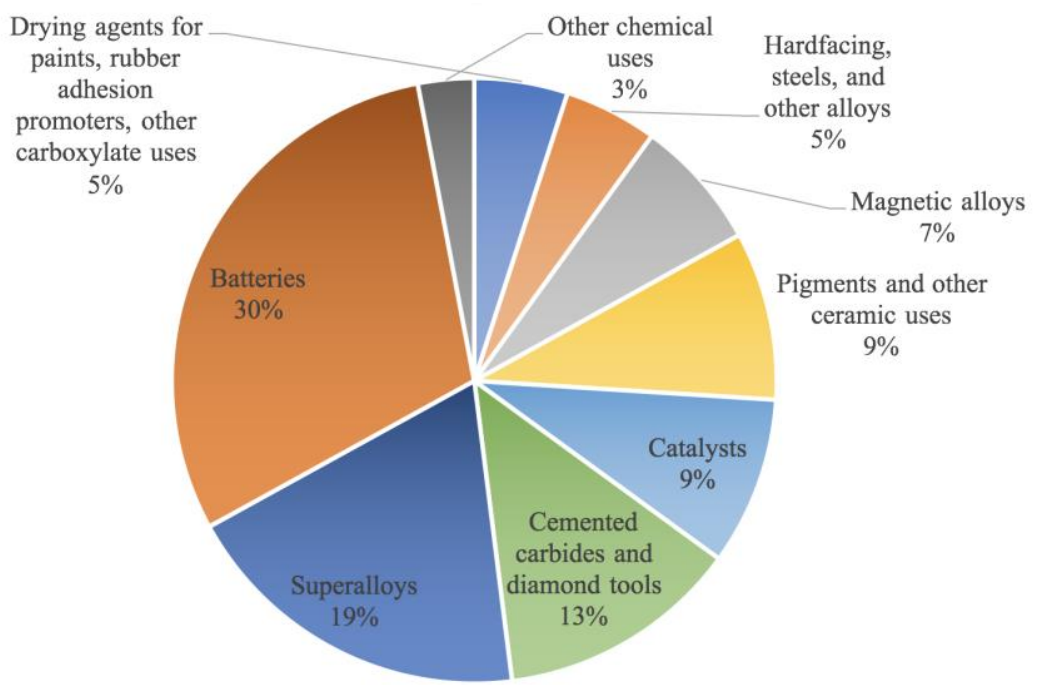

Figure 1. Main cobalt uses according to Slack et al. (2017), in relative percentages of Co metal equivalent used.

Figures 1 and 2 show respectively the various cobalt and lithium uses in 2017 expressed in relative percentages. 


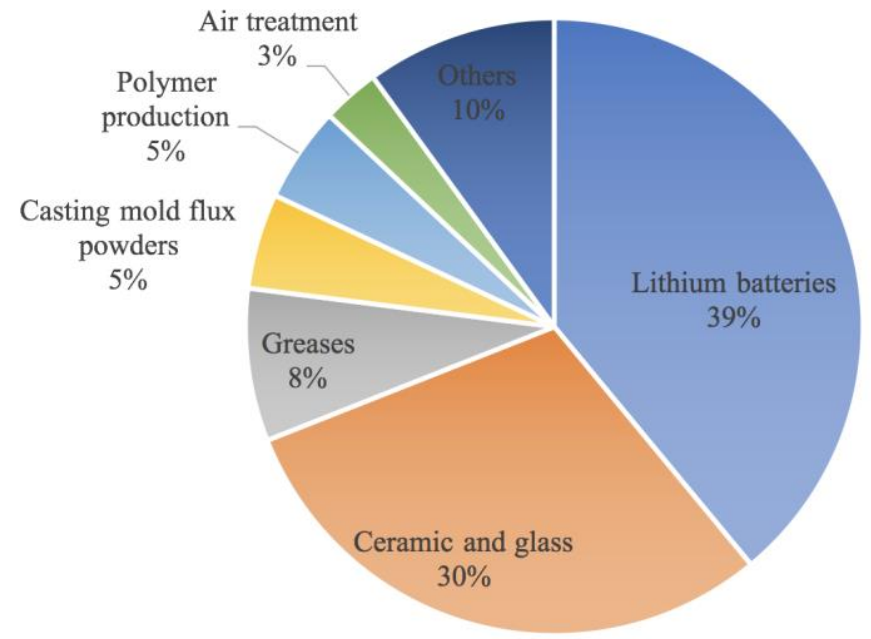

Figure 2. Main lithium uses according to Jaskula (2017), in relative percentages of Li metal equivalent used.

The use of Li-ion batteries for electric cars and cobalt cathode materials manufactured for these rechargeable batteries could potentially increase demand significantly. According to Hao et al., (2017), it is expected that increasing global demand for electric vehicles will mean that global lithium consumption will also experience substantially greater demands over the next few decades. One of the reasons why this happens is because the advances in lithium-ion (Li-ion) battery technology as well as automotive technological advances ushered in by hybrid vehicles, have made it possible to design and manufacture electric vehicles with better performance than their gasoline-powered counterparts.

According to Baur and Todorova (2017), the effort being made to develop an affordable electric vehicle able to travel long distances with a single charge is substantial. Specifically, the energy density of batteries has improved steadily over the past two decades, while its price has fallen by $60 \%$ over the past decade. According to 
The Economist (2017), the cost of lithium-ion cells (the basic components of batteries) last year was in the range of \$130-200. Following Global EV Outlook (2017), new registrations of electric cars have surpassed 750 thousand sales worldwide. The global electric car stock reached 2 million vehicles in 2016 after crossing the 1 million threshold in 2015. Figure 3 represents the evolution of the global electric car stock between 2010 until 2016.

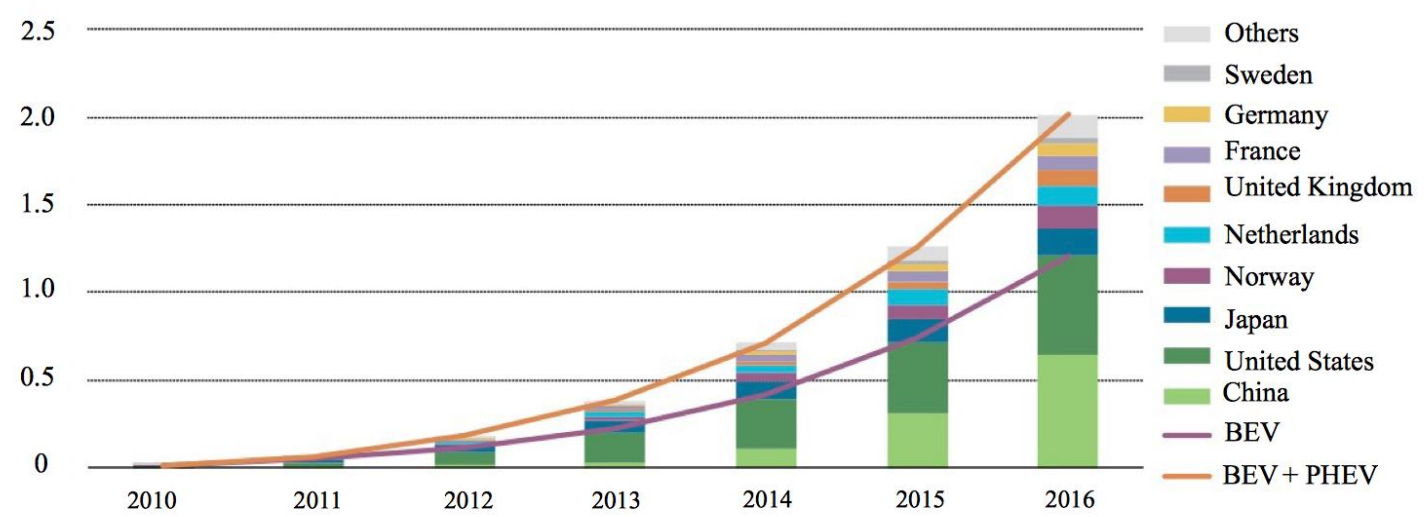

Figure 3. Evolution of the global electric car stock (2010-2016). Sources: Global EV outlook 2017.

Market share represented in Figure 3, is the share of new registrations of electric cars in the total of all PLDVs. ${ }^{1}$ By countries, electric cars in Norway represent $29 \%$ of the domestic market share; the Netherlands achieved $6.4 \%$ of the electric car market share, and Sweden 3.4\%. China, France and the United Kingdom have a domestic electric car market share close to $1.5 \%$, being China the largest electric car market, accounting for more than $40 \%$ of the electric cars sold in the world and more than double the amount sold in the United States.

Global EV Outlook (2017) indicates that until 2015, the United States accounted for the largest share of the global electric car stock. In 2016, China became the country with the largest electric car stock, with about a third of the global total. With more than

\footnotetext{
${ }^{1}$ Electric cars include battery-electric, plug-in hybrid electric, and fuel cell electric passenger light-duty vehicles (PLDVs). They are commonly referred to as BEVs, PHEVs and FCEVs in the EV outlook 2017 report. The scope of Global EV outlook (2017) is limited to BEVs and PHEVs.
} 
200 million electric two-wheelers ${ }^{2}, 3$ to 4 million low-speed electric vehicles (LSEVs) and more than 300 thousand electric buses, China is the global leader in the electrification of other transport modes. World Oil Outlook (2016) from OPEC indicates that demand in the road transportation sector is set to grow by $6.2 \mathrm{mb} / \mathrm{d}$ over the forecast period. However, growth is unequally distributed. According to their estimations for OECD countries, demand in this sector is expected to drop by $6.7 \mathrm{mb} / \mathrm{d}$ between 2015 and 2040 in line with a strong decline in use per vehicle (OPV). The result of car fleet efficiency improvements, the penetration of alternative fuel vehicles and the declining average vehicle miles travelled (VMT), far outbalances the moderate increase in the passenger car and commercial vehicle fleet. Bloomberg (2016) indicates that the price of lithium-ion battery packs for electric cars has reduced by 65 percent since 2010 and albeit with uncertain timing, further breakthroughs in this area are likely. It is also reasonable to assume that technology will improve, thus reducing the lithium and cobalt requirements, with a corresponding effect on production.

In developing countries, demand is anticipated to increase by $12.6 \mathrm{mb} / \mathrm{d}$ between 2015 and 2040. Contrary to what is foreseen in the OECD, the expected decline in OPV in developing countries is not enough to compensate for the significant increase in the vehicle fleet.

In this paper, we examine the time series properties of cobalt and lithium prices from May 2010 until July 2017 using daily and monthly data. Also, we examine the World, European, United States and Japanese automobile and components data using daily and monthly data from May 2010 until August 2017. The dataset was obtained from Bloomberg (2016). The techniques used are based on the concepts of fractional integration and cointegration.

2 "two-wheelers" refers to motorcycles and excludes bicycles. 
The rest of the paper is structured as follows. Section 2 briefly reviews the literature on these metals and components. Section 3 presents the methodology applied in the paper. Section 4 describes the data and present the main empirical results, while Section 5 concludes the paper.

\section{Literature review}

A limited number of studies consider the automotive industry and lithium and cobalt prices. Consequently, to understand the behavior of automobile and its components industry, it is also important to understand the lithium and cobalt industries and their prices.

The most common method used in the literature to assess past, present and future stocks and flows of metals is the Dynamic Material Flow Analysis (MFA), which is a systemic assessment of the flows and stocks of materials defined in space and time (Brunner and Rechberger, 2004) that can help policy makers, researchers, and industry gain insights into addressing lithium and cobalt concerns.

As far as the empirical literature is concerned, Ziemann et al. (2012) proposed the first global lithium flow model and found a noticeable discrepancy between production and consumption. Numerous studies investigated the global lithium supplydemand relationship within the context of corresponding lithium-ion battery demand (Habib and Wenzel, 2014; Pehlken et al., 2017; Speirs et al., 2014; Vikström et al., 2013; Chang et al., 2009; etc.). Global-level MFA studies have been conducted for many commodities such as aluminum (Liu and Müller, 2013) and copper (Gerst, 2009). Also, many other papers (Grosjean et al., 2012; Yaksic and Tilton, 2009; and Gruber et al., 2012) consider primarily the available lithium inventory (either as reserves or as resources) and compare this with estimated future consumption volumes, without 
regarding possible or likely production rates. On the other hand, Gil-Alana and Monge (2018) analyzed the statistical properties of U.S. lithium production from 1900 until 2008, the estimated lithium consumption in the U.S. from 1900 to 2014, and the global lithium production (1925 - 2014), with annual data and using fractional integration or I(d) methods, adding a better understanding in the behavior of lithium production and estimated lithium consumption.

This empirical paper pays particular attention to transitory shocks (associated with trend stationary processes) and permanent shocks (related to difference stationary processes), focusing on the degree of persistence observed in the series. The contributions of the paper are twofold. First, to our knowledge this is the first paper that proposes to study the time series properties of lithium and cobalt prices and World, European, United States and Japanese automobile and automobile components using daily and monthly data. Second, in this paper we use some recently developed methods based on the concepts of long run dependence and long memory using fractional integration and cointegration techniques. The methodology used in the second part of the research is similar to the one applied in Monge et al. (2017), though no long run equilibrium relationships were examined in that work. Fractional integration is more general than the standard methods that exclusively use integer orders of differentiation (i.e., AR(I)MA models), allowing for a higher degree of flexibility in the dynamic specification of the model.

\section{Methodology}

As earlier mentioned we use techniques based on long memory and fractional integration. For this purpose we need to define first an integrated process of order 0 or $\mathrm{I}(0)$. In the time domain, an $\mathrm{I}(0)$ process is defined as a covariance stationary process 
with the infinite sum of the autocovariances being finite. Alternatively, in the frequency domain, it is defined as a process with a spectral density function that is positive and finite at the zero frequency. This is a very broad definition that includes not only the white noise but also weak autocorrelation of the stationary and invertible ARMA form. On the other extreme, we can have a nonstationary process, defined as having a unit root or integrated of order 1, i.e., I(1), which, in its simplest form, is the random walk model of form:

$$
(1-B) x_{t}=u_{t}, \quad t=1,2, \ldots
$$

where $B$ is the backshift operator $\left(B x_{t}=x_{t-1}\right)$ and $u_{t}$ is a white noise process. Note that if $u_{t}$ is an $\operatorname{ARMA}(\mathrm{p}, \mathrm{q})$ process, $x_{t}$ is then an $\operatorname{ARIMA}(\mathrm{p}, 1, \mathrm{q})$ process. However, the stationary $\mathrm{I}(0)$ and the nonstationary $\mathrm{I}(1)$ cases are both particular cases within a more flexible type of model known as fractionally integrated or I(d) where d can be any real value. Thus, we will examine in this paper models of form:

$$
(1-B)^{d} x_{t}=u_{t}, \quad t=1,2, \ldots,
$$

where $u_{t}$ is $\mathrm{I}(0)$ and $\mathrm{d}$ can be 0 , a value between 0 and 1,1 , or even above 1 . (See, GilAlana and Hualde, 2009 for a review of these models).

Note that the estimation of $\mathrm{d}$ becomes crucial when using this approach. Thus, for example, from a statistical viewpoint $x_{t}$ is covariance stationary as long as $d$ is smaller than 0.5 , while it is nonstationary for $d \geq 0.5$ in the sense that the variance of the partial sums increase in magnitude with $d$. However, the differencing parameter $d$ is also important from an economic viewpoint. Thus, if $d$ is smaller than 1 , shocks will have a transitory nature and their effects will disappear by themselves in the long run, contrary to what happens if $d \geq 1$ where shocks are not mean reverting and will persist forever. Thus, $\mathrm{d}$ can be viewed as an indicator of the degree of persistence, the higher its value is, the higher the degree of persistence in the data is. 
The estimation and testing approaches employed in this work are standard in this literature and are based on Dahlhaus (1989), Sowell (1992) and Robinson (1994, 1995) for the univariate work, and Engle and Granger (1987), Cheung and Lai (1993) and GilAlana (2003) and others for the multivariate (cointegration) work. The results were very robust across the different methods.

\section{Empirical results}

\subsection{Data}

The data examined in this work, obtained from Bloomberg database, correspond to:

- Cobalt prices

- Solactive Global Lithium Index ${ }^{3}$

- MSCI World Automobiles and Components Index

- MSCI Europe Automobiles and Components Index

- $\quad$ MSCI United States Automobiles and Components Index

- MSCI Japan Automobiles and Components Index

The daily time period analysed is from 19.05.2010 until 07.08.2017, and the monthly time period analysed is from May 2010 until August 2017.

Figure 4 plots the automobile and components index for the World, Europe, the United States and Japan and the cobalt prices and solactive global index.

\footnotetext{
${ }^{3}$ The Solactive Global Lithium Index tracks the performance of the largest and most liquid listed companies active in exploration and/or mining of Lithium or the production of Lithium batteries. The index is calculated as a total return index in USD and adjusted semi-annually.
} 


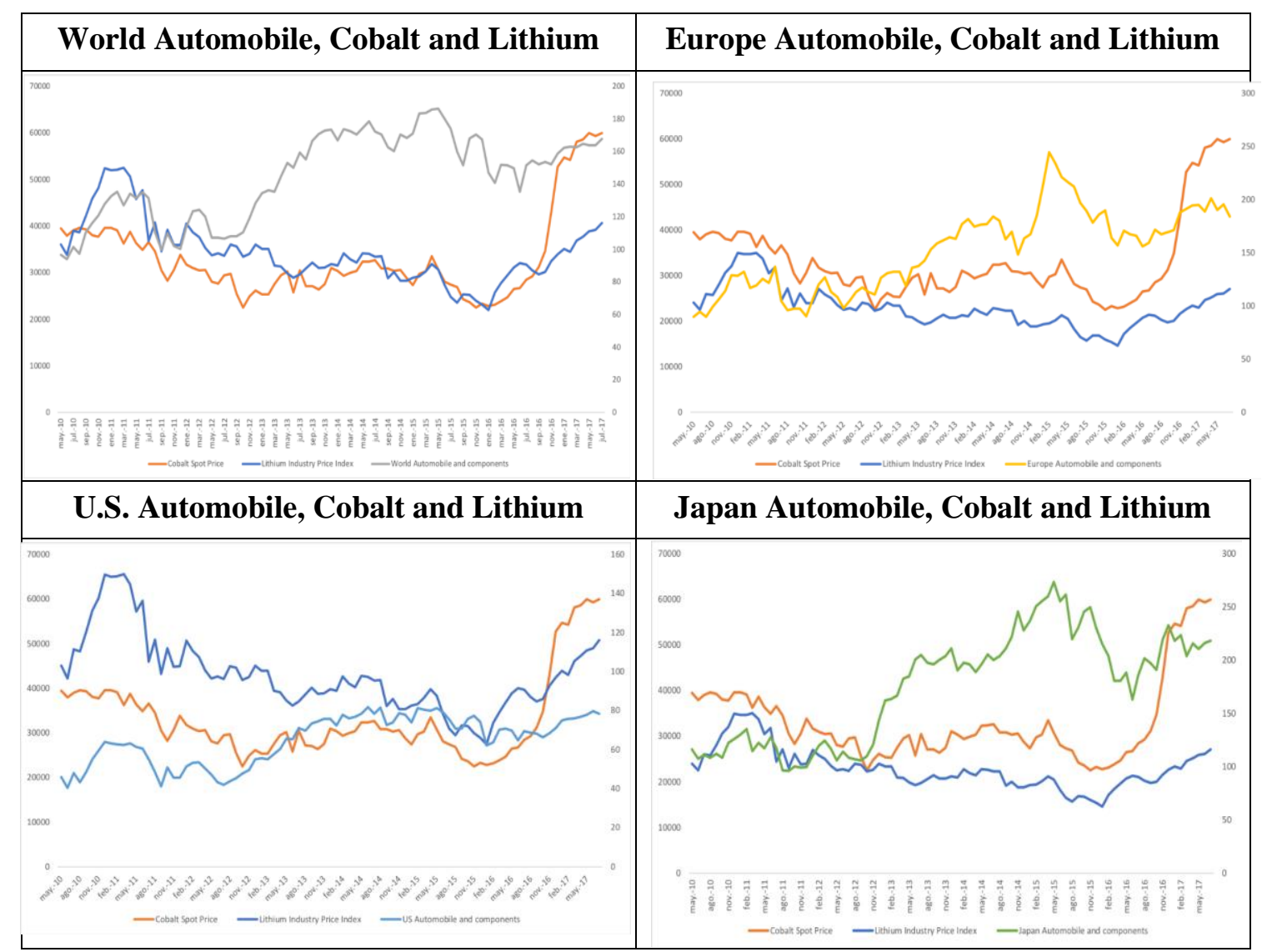

Figure 4: Time series plots

\subsection{Empirical results}

The first thing we have done in this section is to estimate $d$ for each of the series, first with the monthly data and then with the daily data. We consider the following model,

$$
y_{t}=\beta_{0}+\beta_{1} t+x_{t}, \quad(1-B)^{d} x_{t}=u_{t}, \quad t=0,1, \ldots
$$

where $y_{t}$ is the observed time series, $\beta_{0}$ and $\beta_{1}$ are unknown coefficients corresponding to an intercept and a linear time trend; and $x_{t}$ is supposed to be integrated of order $d$ (or $\mathrm{I}(d)$ ) implying thus that $u_{t}$ in the second equation in (3) is $\mathrm{I}(0)$. We report in Table 1 the estimates of $d$ (and their corresponding 95\% intervals) for the three cases of no regressors, an intercept, and an intercept with a linear time trend, assuming that the errors are white noise and autocorrelated, in the latter case using the exponential 
spectral model of Bloomfield (1973). ${ }^{4}$ These estimates were obtained using the Whittle function in the frequency domain using the parametric approaches of Dahlhaus (1989) and Robinson (1994). Almost identical results were obtained when using maximum likelihood approaches (Sowell, 1992, Beran, 1995).

Starting with the monthly data (in Table 1), the results support the I(1) hypothesis in the majority of the cases, the only exceptions being $L M E$ cobalt (with the original data and in $\operatorname{logs}$ ) with white noise errors, and lithium in the context of autocorrelated disturbances, where the estimated value of $d$ is found to be significantly higher than 1. In all the other cases, the I(1) null hypothesis cannot be rejected.

Table 1: Estimates of $d$ based on a monthly basis

\begin{tabular}{|c|c|c|c|}
\hline \multicolumn{4}{|c|}{ i) No autocorrelation } \\
\hline & No regressors & An intercept & A linear time trend \\
\hline LME Cobalt Spot & $1.035(0.929,1.186)$ & $1.184(1.071,1.356)$ & $1.188(1.073,1.358)$ \\
\hline LME Cobalt (in logs) & $0.961(0.837,1.140)$ & $1.117(1.005,1.285)$ & $1.119(1.005,1.287)$ \\
\hline Sollit Lithium & $1.018(0.918,1.154)$ & $0.959(0.851,1.097)$ & $0.960(0.852,1.097)$ \\
\hline WORLD Auto Index & $0.995(0.865,1.176)$ & $0.994(0.839,1.216)$ & $0.995(0.849,1.211)$ \\
\hline E.U. Auto Comp. Index & $0.938(0.794,1.131)$ & $0.970(0.802,1.203)$ & $0.969(0.801,1.202)$ \\
\hline U.S. Auto Comp. Index & $0.933(0.819,1.083)$ & $0.926(0.791,1.114)$ & $0.927(0.796,1.112)$ \\
\hline JAPAN Auto Comp. Index & $0.911(0.773,1.093)$ & $0.946(0.829,1.113)$ & $0.945(0.825,1.112)$ \\
\hline \multicolumn{4}{|c|}{ i) With (Bloomfield) autocorrelation } \\
\hline & No regressors & An intercept & A linear time trend \\
\hline LME Cobalt Spot & $1.067(0.883,1.310)$ & $1.089(0.913,1.338)$ & $1.089(0.911,1.340)$ \\
\hline LME Cobalt (in logs) & $0.903(0.689,1.221)$ & $1.047(0.849,1.290)$ & $1.048(0.853,1.292)$ \\
\hline Sollit Lithium & $1.248(1.029,1.581)$ & $1.388(1.069,1.976)$ & $1.385(1.069,2.174)$ \\
\hline WORLD Auto Index & $0.942(0.669,1.244)$ & $0.733(0.510,1.076)$ & $0.769(0.529,1.081)$ \\
\hline E.U. Auto Comp. Index & $0.809(0.443,1.171)$ & $0.711(0.512,1.145)$ & $0.688(0.407,1.144)$ \\
\hline
\end{tabular}

\footnotetext{
${ }^{4}$ The model of Bloomfield (1973) is a non-parametric approach that produces autocorrelations decaying exponentially as in the AR case.
} 


\begin{tabular}{|c|c|c|c|}
\hline U.S. Auto Comp. Index & $1.067(0.932,1.369)$ & $0.849(0.519,1.200)$ & $\mathbf{0 . 8 5 1}(\mathbf{0 . 5 9 8}, \mathbf{1 . 1 8 9})$ \\
\hline JAPAN Auto Comp. Index & $0.878(0.549,1.284)$ & $\mathbf{0 . 9 6 0}(\mathbf{0 . 7 2 9}, \mathbf{1 . 3 1 8})$ & $0.959(0.717,1.317)$ \\
\hline
\end{tabular}

In bold, the significant models according to the deterministic terms.

Using daily data (in Table 2) the results are more sensitive to the choice of the error term. Thus, for example, for cobalt, the I(1) hypothesis is rejected in favor of smaller degrees of integration, but the contrary happens with autocorrelation, where the $\mathrm{I}(1)$ null is rejected in favor of $\mathrm{I}(d, d>1)$; for lithium, the estimated value of $\mathrm{d}$ is found to be significantly higher than 1 with no autocorrelation, but the I(1) hypothesis cannot be rejected under autocorrelation. The same lack of robustness occurs for the automobile components: for the World data, $\mathrm{d}$ is higher than 1 with no autocorrelation but the I(1) hypothesis cannot be rejected under autocorrelation; for the EU data, $\mathrm{d}$ is higher than 1 with white noise errors but significantly smaller than 1 with autocorrelation; for the remaining two series (US and Japan) the I(1) hypothesis cannot be rejected in either of the two models examined.

Table 2: Estimates of $\mathbf{d}$ based on a daily basis

\begin{tabular}{|c|c|c|c|}
\hline \multicolumn{5}{|c|}{ i) No autocorrelation } \\
\hline & No regressors & An intercept & A linear time trend \\
\hline LME Cobalt Spot & $0.999(0.973,1.027)$ & $\mathbf{0 . 9 4 4}(\mathbf{0 . 9 2 7}, \mathbf{0 . 9 6 4})$ & $0.944(0.926,0.963)$ \\
\hline LME Cobalt (in logs) & $0.999(0.971,1.029)$ & $\mathbf{0 . 9 3 1}(\mathbf{0 . 9 1 2 , 0 . 9 5 3 )}$ & $0.931(0.912,0.953)$ \\
\hline Sollit Lithium & $1.008(0.981,1.038)$ & $\mathbf{1 . 0 8 6}(\mathbf{1 . 0 5 3}, \mathbf{1 . 1 2 4})$ & $1.086(1.053,1.124)$ \\
\hline \hline WORLD Auto Index & $1.023(0.993,1.054)$ & $\mathbf{1 . 1 1 4}(\mathbf{1 . 0 7 6}, \mathbf{1 . 1 5 7})$ & $1.114(1.076,1.157)$ \\
\hline E.U. Auto Comp. Index & $1.027(0.995,1.062)$ & $\mathbf{1 . 0 3 8}(\mathbf{1 . 0 0 5}, \mathbf{1 . 0 7 6})$ & $1.038(1.005,1.075)$ \\
\hline U.S. Auto Comp. Index & $0.993(0.965,1.025)$ & $\mathbf{1 . 0 1 5}(\mathbf{0 . 9 8 4 , 1 . 0 5 1})$ & $1.015(0.984,1.051)$ \\
\hline JAPAN Auto Comp. Index & $0.992(0.963,1.024)$ & $\mathbf{0 . 9 9 0}(\mathbf{0 . 9 6 1 , 1 . 0 2 3})$ & $0.990(0.961,1.023)$ \\
\hline \multicolumn{5}{|c|}{ i) With (Bloomfield) autocorrelation } & \\
\hline & No regressors & An intercept & A linear time trend \\
\hline
\end{tabular}




\begin{tabular}{|c|c|c|c|}
\hline LME Cobalt Spot & $1.029(0.983,1.079)$ & $\mathbf{1 . 0 5 5}(\mathbf{1 . 0 2 0}, \mathbf{1 . 0 8 8})$ & $1.056(1.020,1.088)$ \\
\hline LME Cobalt (in logs) & $0.993(0.952,1.055)$ & $\mathbf{1 . 0 3 7}(\mathbf{1 . 0 0 2}, \mathbf{1 . 0 7 7})$ & $1.037(1.002,1.077)$ \\
\hline Sollit Lithium & $1.019(0.974,1.071)$ & $\mathbf{1 . 0 3 1}(\mathbf{0 . 9 7 4 ,} \mathbf{1 . 0 7 9})$ & $1.031(0.974,1.079)$ \\
\hline \hline WORLD Auto Index & $0.978(0.937,1.029)$ & $\mathbf{0 . 9 6 3}(\mathbf{0 . 9 2 1 , ~ 1 . 0 1 6 )}$ & $0.963(0.922,1.016)$ \\
\hline E.U. Auto Comp. Index & $0.963(0.921,1.014)$ & $\mathbf{0 . 9 5 3}(\mathbf{0 . 9 1 2}, \mathbf{0 . 9 9 8})$ & $0.953(0.912,0.998)$ \\
\hline U.S. Auto Comp. Index & $0.999(0.958,1.052)$ & $\mathbf{0 . 9 5 7}(\mathbf{0 . 9 2 1}, \mathbf{1 . 0 0 9})$ & $0.957(0.921,1.009)$ \\
\hline JAPAN Auto Comp. Index & $0.970(0.937,1.033)$ & $\mathbf{0 . 9 7 1}(\mathbf{0 . 9 2 4}, \mathbf{1 . 0 1 7})$ & $0.971(0.924,1.017)$ \\
\hline
\end{tabular}

In bold, the significant models according to the deterministic terms.

Due to the disparity in these results, we also computed them based on a semiparametric method where no functional form is imposed on the error term. Here we use the Whittle semiparametric approach as initially proposed by Robinson (1995). ${ }^{5}$ It is a "local" Whittle estimator, in the frequency domain, in the sense that it uses a band of local frequencies degenerating to zero. This estimator is robust to a certain degree of conditional heteroscedasticity and is more efficient than other more recent semiparametric competitors.

Table 3 focusses on monthly data, while Table 4 reports the results with daily data, and in the two tables we display the estimated values of $\mathrm{d}$ for a selected group of bandwidth numbers. ${ }^{6}$

Table 3: Estimates of $\mathbf{d}$ for the monthly data with a semiparametric method

\begin{tabular}{|c|c|c|c|c|c|c|c|}
\hline Series & 6 & 7 & 8 & 9 & 10 & 11 & 12 \\
\hline LME Cobalt Spot & 1.479 & 1.375 & 1.375 & 1.384 & 1.411 & 1.437 & 1.415 \\
\hline LME Cobalt (in logs) & 1.466 & 1.327 & 1.339 & 1.348 & 1.355 & 1.377 & 1.369 \\
\hline Sollit Lithium & $\mathbf{1 . 2 3 2}$ & $\mathbf{0 . 9 9 1}$ & $\mathbf{0 . 9 7 1}$ & $\mathbf{1 . 0 4 4}$ & $\mathbf{1 . 1 2 8}$ & $\mathbf{1 . 1 7 6}$ & 1.238 \\
\hline \hline WORLD Auto Ind. & $\mathbf{1 . 0 7 5}$ & $\mathbf{0 . 9 2 2}$ & $\mathbf{1 . 0 5 1}$ & $\mathbf{0 . 9 8 8}$ & $\mathbf{0 . 9 1 5}$ & $\mathbf{0 . 9 5 2}$ & $\mathbf{0 . 9 8 8}$ \\
\hline
\end{tabular}

\footnotetext{
${ }^{5}$ Though this method has been improved by many authors (Velasco, 1999, Phillips and Shimotsu, 2004, 2005; Abadir et al., 2007) all these methods required additional user-chosen parameters and the results are very sensitive to these numbers.

${ }^{6}$ The choice of the bandwidth $(\mathrm{m})$ shows the trade-off between the bias and the variance in the estimation of $\mathrm{d}$ : the asymptotic variance is decreasing with $\mathrm{m}$ while the bias is growing with $\mathrm{m}$.
} 


\begin{tabular}{|c|c|c|c|c|c|c|c|}
\hline E.U. Auto Comp. & 0.577 & 0.500 & 0.598 & 0.632 & 0.619 & 0.706 & 0.703 \\
\hline U.S. Auto Comp. & $\mathbf{1 . 0 5 4}$ & $\mathbf{0 . 8 5 9}$ & $\mathbf{0 . 9 2 7}$ & $\mathbf{0 . 9 9 3}$ & $\mathbf{0 . 9 2 4}$ & $\mathbf{0 . 9 9 4}$ & $\mathbf{1 . 0 0 1}$ \\
\hline JAPAN Auto Comp. & $\mathbf{0 . 8 6 9}$ & $\mathbf{1 . 0 0 5}$ & $\mathbf{1 . 0 3 3}$ & $\mathbf{1 . 0 9 0}$ & $\mathbf{1 . 1 4 8}$ & $\mathbf{1 . 2 2 0}$ & $\mathbf{1 . 2 2 6}$ \\
\hline \hline Lower 95\% I(1) band & 0.664 & 0.689 & 0.709 & 0.725 & 0.739 & 0.752 & 0.762 \\
\hline Upper 95\% I(1) band & 1.335 & 1.310 & 1.290 & 1.274 & 1.260 & 1.247 & 1.237 \\
\hline
\end{tabular}

In bold, evidence of I(1) behavior at the 5\% level.

Table 4: Estimates of $\mathbf{d}$ for the daily data with a semiparametric method

\begin{tabular}{|c|c|c|c|c|c|c|c|}
\hline Series & 41 & 42 & 43 & 44 & 45 & 46 & 47 \\
\hline LME Cobalt Spot & 1.196 & 1.203 & 1.202 & 1.207 & 1.165 & 1.173 & 1.171 \\
\hline LME Cobalt (in logs) & 1.168 & 1.166 & 1.169 & 1.176 & 1.140 & 1.151 & 1.154 \\
\hline Sollit Lithium & $\mathbf{1 . 0 2 4}$ & $\mathbf{1 . 0 3 0}$ & $\mathbf{1 . 0 2 4}$ & $\mathbf{1 . 0 2 8}$ & $\mathbf{1 . 0 3 0}$ & $\mathbf{1 . 0 3 4}$ & $\mathbf{1 . 0 3 4}$ \\
\hline \hline WORLD Auto Ind. & $\mathbf{0 . 9 7 9}$ & $\mathbf{0 . 9 8 5}$ & $\mathbf{0 . 9 9 8}$ & $\mathbf{1 . 0 0 4}$ & $\mathbf{1 . 0 1 9}$ & $\mathbf{1 . 0 3 5}$ & $\mathbf{1 . 0 1 4}$ \\
\hline E.U. Auto Comp. & $\mathbf{0 . 9 7 0}$ & $\mathbf{0 . 9 7 7}$ & $\mathbf{0 . 9 8 6}$ & $\mathbf{0 . 9 9 8}$ & $\mathbf{1 . 0 0 7}$ & $\mathbf{1 . 0 0 9}$ & $\mathbf{1 . 0 1 0}$ \\
\hline U.S. Auto Comp. & $\mathbf{0 . 9 8 1}$ & $\mathbf{0 . 9 9 2}$ & $\mathbf{1 . 0 0 0}$ & $\mathbf{0 . 9 8 5}$ & $\mathbf{0 . 9 9 2}$ & $\mathbf{0 . 9 6 4}$ & $\mathbf{0 . 9 6 7}$ \\
\hline JAPAN Auto Comp. & $\mathbf{1 . 0 2 1}$ & $\mathbf{1 . 0 0 2}$ & $\mathbf{0 . 9 9 1}$ & $\mathbf{1 . 0 0 0}$ & $\mathbf{1 . 0 0 0}$ & $\mathbf{1 . 0 0 7}$ & $\mathbf{1 . 0 1 3}$ \\
\hline \hline Lower 95\% I(1) band & 0.871 & 0.873 & 0.874 & 0.876 & 0.877 & 0.878 & 0.888 \\
\hline Upper 95\% I(1) band & 1.128 & 1.126 & 1.125 & 1.123 & 1.122 & 1.121 & 1.119 \\
\hline
\end{tabular}

In bold, evidence of I(1) behavior at the $5 \%$ level.

With the monthly data, the results support the I(1) specification for sollit lithium, in the case of World, US and Japan. However, with daily data, the evidence is found for lithium and for the four auto-related series. Thus, in what follows, we focus on bivariate relationships between the lithium and the four automobile components using daily data in order to check if there exist long run equilibrium relationships. For this purpose, we use a version of the classical two-step method proposed in Engle and Granger (1987) for testing cointegration in a bivariate representation, regressing first one variable (lithium) against the other (each of the automobile components), i.e., 


$$
y_{t}=\alpha+\beta z_{t}+x_{t}, \quad t=1,2, \ldots
$$

and then, testing the order of integration in the estimated residuals from the above regression. However, instead of using standard unit root methods as was done in Engle and Granger (1987) we test for any real value for the differencing parameter (See, e.g., Cheung and Lai, 1993, and Gil-Alana, 2003). The results based on this approach, for the two cases of uncorrelated and autocorrelated (Bloomfield) errors are displayed in Table 5, and we observe that we cannot reject the hypothesis of unit roots in any single case, discarding thus the possibility of long run equilibrium relationships among the variables.

Table 5: Testing for cointegration in the (potentially) cointegrating residuals

\begin{tabular}{|c|c|c|c|c|}
\hline & $\alpha$ & $\beta$ & $\begin{array}{c}\text { No } \\
\text { autocorrelation }\end{array}$ & Autocorrelation \\
\hline Lithium / World & $\begin{array}{c}145.61 \\
(-0.327)\end{array}$ & $\begin{array}{c}-0.327 \\
(-21.85)\end{array}$ & $\begin{array}{c}1.03 \\
(1.01,1.07)\end{array}$ & $\begin{array}{c}1.10 \\
(1.04,1.17)\end{array}$ \\
\hline Lithium / E.U. & $\begin{array}{c}135.13 \\
(8499)\end{array}$ & $\begin{array}{c}-0.242 \\
(-23.93)\end{array}$ & $\begin{array}{c}1.04 \\
(1.01,1.07)\end{array}$ & $\begin{array}{c}1.10 \\
(1.05,1.16)\end{array}$ \\
\hline Lithium / U.S. & $\begin{array}{c}131.30 \\
(58.86)\end{array}$ & $\begin{array}{c}-0.509 \\
(-15.10)\end{array}$ & $\begin{array}{c}1.03 \\
(1.01,1.06)\end{array}$ & $\begin{array}{c}1.09 \\
(1.04,1.16)\end{array}$ \\
\hline Lithium / Japan & 138.63 & -0.230 & 1.04 & 1.11 \\
& $(115.3)$ & $(-35.09)$ & $(1.01,1.07)$ & $(1.05,1.18)$ \\
\hline
\end{tabular}

The values in parenthesis in the second and third columns refer to the corresponding $t$-values. Those in columns 4 and 5 are $95 \%$ confidence bands.

As a final approach in this context, we conduct a regression of lithium $\left(y_{t}\right)$ against each of the automobile components $\left(z_{t}\right)$, using the appropriate differences for each series, and estimating the coefficients of such a relationship. More specifically, we use the method developed in Robinson (1994) assuming that the automobile components are in this context exogenous in the model. The examined model is now:

$$
y_{t}=\alpha+\beta z_{t}+x_{t}, \quad(1-B)^{d} x_{t}=u_{t}, \quad t=1,2, \ldots
$$

estimating simultaneously the two equations. Thus, the two equalities in (4) becomes: 


$$
y_{t}^{*}=\alpha 1_{t}^{*}+\beta z_{t}^{*}+u_{t}, \quad t=1,2, \ldots
$$

where $y_{t}^{*}=(1-B)^{d} y_{t} ; \quad 1_{t}^{*}=(1-B)^{d} 1_{t}$ and $z_{t}^{*}=(1-B)^{d} z_{t}$. The results in terms of the estimated coefficients are displayed across Table 6 .

Table 6: Testing the linear regression among the variables

\begin{tabular}{|c|c|c|c|c|c|c|}
\hline & \multicolumn{3}{|c|}{ No autocorrelation } & \multicolumn{3}{c|}{ Autocorrelation } \\
\hline & $\mathrm{d}$ & $\alpha$ & $\beta$ & $\mathrm{d}$ & $\mathrm{A}$ & $\beta$ \\
\hline \multirow{2}{*}{ Lithium / World } & 1.09 & $\mathbf{9 9 . 2 3 2}$ & $\mathbf{0 . 0 3 7 4}$ & 1.02 & $\mathbf{9 8 . 8 4 2}$ & $\mathbf{0 . 0 3 9 4}$ \\
& $(1.05,1.13)$ & $\mathbf{( 4 0 . 5 5 )}$ & $\mathbf{( 1 . 8 2 )}$ & $(0.97,1.08)$ & $\mathbf{( 4 0 . 6 0 )}$ & $\mathbf{( 1 . 9 3 )}$ \\
\hline \multirow{2}{*}{ Lithium / E.U. } & 1.09 & $\mathbf{1 0 5 . 9 1 3}$ & $\mathbf{- 0 . 0 3 4 1}$ & 1.04 & $\mathbf{1 0 5 . 4 7 0}$ & $\mathbf{- 0 . 0 3 0 6}$ \\
& $(1.06,1.13)$ & $\mathbf{( 6 1 . 2 0 )}$ & $\mathbf{( - 2 . 6 6 )}$ & $(0.99,1.10)$ & $\mathbf{( 6 0 . 8 0 )}$ & $\mathbf{( - 2 . 3 8 )}$ \\
\hline \multirow{2}{*}{ Lithium / U.S. } & 1.08 & $\mathbf{9 7 . 8 6 2}$ & $\mathbf{0 . 1 1 0 4}$ & 1.01 & $\mathbf{9 7 . 2 7 9}$ & $\mathbf{0 . 1 1 9 1}$ \\
& $(1.05,1.12)$ & $\mathbf{( 4 6 . 7 8 )}$ & $\mathbf{( 3 . 1 5 )}$ & $(0.96,1.07)$ & $\mathbf{( 4 6 . 5 1 )}$ & $\mathbf{( 3 . 3 9 )}$ \\
\hline \multirow{2}{*}{ Lithium / Japan } & 1.09 & $\mathbf{1 0 2 . 1 5 2}$ & 0.0072 & 1.03 & $\mathbf{1 0 1 . 8 5 6}$ & 0.0084 \\
& $(1.05,1.13)$ & $\mathbf{( 5 5 . 8 9 )}$ & $(0.65)$ & $(0.98,1.09)$ & $\mathbf{( 5 5 . 5 3 )}$ & $(0.75)$ \\
\hline
\end{tabular}

The values in parenthesis in columns 2 and 5 are 95\% confidence bands. Those in columns 3, 4, 6 and 7 are t-values.

We observe here that the estimated values of $d$ are above 1 under no autocorrelation and within the $\mathrm{I}(1)$ case under Bloomfield disturbances. More importantly, the slope coefficients are significant for the World, EU and US automobile components but not for the case of Japan. Moreover, though the relationship is significantly positive in the cases of World and the US, it is negative for the case of the EU.

\section{Conclusions}

In this article, our objective and focus have been first to analyze the statistical properties of the largest and most liquid listed companies active in exploration and/or mining of lithium or the production of lithium batteries collected in the Solactive Global Index, the cobalt prices and the MSCI Automobiles and Components Index from the World, 
Europe, United States and Japan. We have used fractional integration and cointegration methods using daily and monthly data from May 2010 until August 2017. In doing so we try to gain a deeper understanding of the behavior of the lithium industry and cobalt prices as well as the behavior of automobiles and their components indices.

We first employed parametric methods, imposing uncorrelated (white noise) and autocorrelated errors for the $d$-differenced process, and the results in terms of the estimated values of $d$ were very heterogeneous across the series and across the model investigated. Due to this disparity, we also computed a semiparametric method where no functional form is imposed on the error term. The results here support the I(1) specification for sollit lithium, World, Europe, US and Japan, especially with the daily data.

Next, we focus on bivariate relationships between the lithium and the four automobile components in order to check if there exist long run equilibrium relationships. The results show that we cannot reject the hypothesis of unit roots in any single case, discarding thus the possibility of long run equilibrium relationships among the variables of interest. Finally, we conduct an $\mathrm{I}(d)$ regression assuming that the automobile components are exogenous in the model, observing that the estimated values of $d$ are above 1 and the slope coefficients are significantly positive in the cases of World and the US Automobile Components.

The conclusions of these results are in line with other research works (e.g. World Oil Outlook, 2017) showing high levels of persistence in the series examined, with orders of integration around or above 1 . This implies that shocks in the series will have permanent effects requiring strong measures to recover the original trends. More research along these lines will be conducted in future papers. 


\section{References}

Abadir, K.M., Distaso, W. and Giraitis, L. 2007. Nonstationarity-extended local Whittle estimation, Journal of Econometrics 141, 1353-1384.

Baur, D. G., Todorova, N. 2017. Automobile Manufacturers and the Price of Oil.

Beran, J. (1995) Maximum likelihood estimation of the differencing parameter for invertible short and long memory ARIMA models, Journal of the Royal Statistical Society, Series B, 57, 659-672.

Bloomfield, P. 1973. An exponential model in the spectrum of a scalar time series. Biometrika, 60, 217-226.

Bloomberg, 2016. Battery cost plunge seen changing automakers most in 100 years. https://www.bloomberg.com/news/articles/2017-02-02/electric-cars-could-cause-oilmarketdisruptionon-par-with-opec.

Brunner, P. H., Rechberger, H. 2004. Practical handbook of material flow analysis. The International Journal of Life Cycle Assessment, 9, 337-338.

Chang, T. C., You, S. J., Yu, B. S., Yao, K. F. 2009. A material flow of lithium batteries in Taiwan. Journal of Hazardous Materials, 163, 910-915.

Cheung, Y.W., Lai, K.S., 1993. A fractional cointegration analysis of purchasing power parity. Journal of Business and Economic Statistics 11, 103-112.

Dahlhaus, R. 1989. Efficient parameter estimation of self-similar processes, Annals of Statistics 17, 1749-1766.

Engle, R. F., Granger, C. W. J. 1987, Cointegration and error correction: Representation, estimation and testing, Econometrica 55, 251-276.

Gerst, M. D. 2009. Linking material flow analysis and resource policy via future scenarios of In-use stock: an example for copper. Environmental Science and Technology, 43, 6320-6325.

Gil-Alana, L. A. 2003. Testing of Fractional Cointegration in Macroeconomic Time Series, Oxford Bulletin of Economic and Statistics, 65, 517-529.

Gil-Alana, L. A., Hualde, J. 2009. Fractional integration and cointegration. An overview with an empirical application. The Palgrave Handbook of Applied Econometrics, 2, 434-472.

Gil-Alana, L. A., Monge, M. 2018. Lithium: production and estimated consumption. Evidence of persistence. Working Paper. Submitted in Resources Policy. 
Global, E. V. Outlook 2017: Accelerating the Global Clean Energy Transition. International Energy Agency: Paris, France.

Grosjean, C., Miranda, P. H., Perrin, M., Poggi, P. 2012. Assessment of world lithium resources and consequences of their geographic distribution on the expected development of the electric vehicle industry. Renewable and Sustainable Reviews, 16, 1735-1744.

Gruber, P., Medina, P., Keoleian, G., Kesler, S., Everson, M., Wallington, T. 2012. Global lithium availability, a constraint for electric vehicles? Journal of Industrial Ecolology, 15, 760-775.

Habib, K., Wenzel, H. 2014. Exploring rare earths supply constraints for the emerging clean energy technologies and the role of recycling. Journal of Cleaner Production, 84, 348-359.

Hao, H., Liu, Z., Zhao, F., Geng, Y., Sarkis, J. 2017. Material flow analysis of lithium in China. Resources Policy, 51, 100-106.

Hockerts, K., Wüstenhagen, R. 2010. Greening Goliaths versus emerging DavidsTheorizing about the role of incumbents and new entrants in sustainable entrepreneurship. Journal of Business Venturing, 25, 481-492.

IPCC fourth assessment report: mitigation of climate change; 2007. http://www.ipcc.ch/pdf/assessment-report/ar4/wg3/ar4-wg3-chapter5.pdf.

Jaskula, B. W. 2017. Mineral Commodity Summaries - Lithium 2017. U.S. Geological Survey.

Johnson, M. W., Suskewicz, J. 2009. How to jump-start the clean economy. Harvard Business Review, 87(11).

Liu, G., Müller, D. B. 2013. Mapping the global journey of anthropogenic aluminum: A trade-linked multilevel material flow analysis. Environmental Science and Technology, 47, 11873-11881.

Monge, M., Gil-Alana, L. A., de Gracia, F. P. 2017. Crude oil price behaviour before and after military conflicts and geopolitical events. Energy, 120, 79-91.

Pehlken, A., Albach, S., Vogt, T. 2017. Is there a resource constraint related to lithium ion batteries in cars?. The International Journal of Life Cycle Assessment, 22, 40-53.

Phillips, P.C.B., Shimotsu, K. 2004. Local Whittle estimation in nonstationary and unit root cases. Annals of Statistics 32, 656-692.

Phillips, P. C. B., Shimotsu, K. 2005. Exact local Whittle estimation of fractional integration. Annals of Statistics 33, 1890-1933. 
Robinson, P. M. 1994. Efficient tests of nonstationary hypotheses, Journal of the American Statistical Association 89, 1420-1437.

Robinson, P. M. 1995. Gaussian semi-parametric estimation of long range dependence, Annals of Statistics 23, 1630-1661.

Slack, J. F., Kimball, B. E., Shedd, K. B. 2017. Cobalt. Critical Mineral Resources of the United States-economic and environmental geology and prospects for future supply. US Geological Survey Professional Paper 1802, F1-F39.

Sowell, F. 1992. Maximum likelihood estimation of stationary univariate fractionally integrated time series models, Journal of Econometrics 53, 165-188.

Speirs, J., Contestabile, M., Houari, Y., Gross, R. 2014. The future of lithium availability for electric vehicle batteries. Renewable and Sustainable Energy Reviews, 35, 183-193.

The Economist. 2017. After electric cars, what more will it take for batteries to change the face of energy? August 12.

Velasco, C. .1999. Gaussian semiparametric estimation of nonstationary time series. Journal of Time Series Analysis 20, 87-127.

Vikström, H., Davidsson, S., Höök, M. 2013. Lithium availability and future production outlooks. Applied Energy, 110, 252-266.

World Oil Outlook. 2016. OPEC, Organization of the Petroleum Exporting Countries. <http://www.opec.org>.

World Oil Outlook. 2017. OPEC, Organization of the Petroleum Exporting Countries. <http://www.opec.org>.

Yaksic, A., Tilton, J. E. 2009. Using the cumulative availability curve to assess the threat of mineral depletion: The case of lithium. Resources Policy, 34, 185-194.

Yong, J. Y., Ramachandaramurthy, V. K., Tan, K. M., Mithulananthan, N. 2015. A review on the state-of-the-art technologies of electric vehicle, its impacts and prospects. Renewable and Sustainable Energy Reviews, 49, 365-385.

Ziemann, S., Weil, M., Schebek, L. 2012. Tracing the fate of lithium. The development of a material flow model. Resources, Conservation and Recycling, 63, 26-34. 